\title{
Prefrontal Cortical GABAergic Dysfunction Contributes to Age-Related Working Memory Impairment
}

\author{
Cristina Bañuelos, ${ }^{1}$ B. Sofia Beas, ${ }^{1}$ Joseph A. McQuail, ${ }^{1}$ Ryan J. Gilbert, ${ }^{1}$ Charles J. Frazier,,${ }^{4,1}$ Barry Setlow, ${ }^{2,1}$ \\ and Jennifer L. Bizon ${ }^{1,2,3}$ \\ ${ }^{1}$ Department of Neuroscience, ${ }^{2}$ Department of Psychiatry, ${ }^{3}$ McKnight Brain Institute, and ${ }^{4}$ Department of Pharmacodynamics, University of Florida, \\ Gainesville, Florida 32610
}

\begin{abstract}
Working memory functions supported by the prefrontal cortex decline in normal aging. Disruption of corticolimbic GABAergic inhibitory circuits can impair working memory in young subjects; however, relatively little is known regarding how aging impacts prefrontal cortical GABAergic signaling and whether such changes contribute to cognitive deficits. The current study used a rat model to evaluate the effects of aging on expression of prefrontal GABAergic synaptic proteins in relation to working memory decline, and to test whether pharmacological manipulations of prefrontal GABAergic signaling can improve working memory abilities in aged subjects. Results indicate that in aged medial prefrontal cortex (mPFC), expression of the vesicular GABA transporter VGAT was unchanged; however, there was a significant increase in expression of the GABA synthesizing enzyme GAD67, and a significant decrease in the primary neuronal GABA transporter GAT-1 and in both subunits of the GABA(B) receptor (GABA(B)R). Expression of VGAT, GAD67, and GAT-1 was not associated with working memory ability. In contrast, among aged rats, GABA(B)R expression was significantly and negatively associated with working memory performance, such that lower GABA(B)R expression predicted better working memory. Subsequent experiments showed that systemic administration of a GABA(B)R antagonist, CGP55845, dose-dependently enhanced working memory in aged rats. This enhancing effect of systemic CGP55845 was reproduced by direct intra-mPFC administration. Together, these data suggest that age-related dysregulation of GABAergic signaling in prefrontal cortex may play a causal role in impaired working memory and that targeting $\mathrm{GABA}(\mathrm{B})$ Rs may provide therapeutic benefit for age-related impairments in executive functions.
\end{abstract}

Key words: aging; CGP55845; executive function; GABA(B) receptor; inhibition; prefrontal cortex

\section{Introduction}

With advancing age, many individuals will experience a significant decline of cognitive capacities supported by the prefrontal cortex (PFC), resulting in deficits across a wide range of adaptive behaviors that are essential for maintaining independence and quality of life (Robbins et al., 1998; Salthouse et al., 2003; Glisky, 2007; Bizon et al., 2012). One fundamental aspect of PFC function is working memory, which involves the ability to maintain a mental representation "in mind" of information that is no longer present in the environment, and to use this representational information to guide future action (Goldman-Rakic, 1996). Within the PFC, maintenance of information in mind following the removal of a sensory stimulus is associated with persistent excitation of pyramidal neurons, providing a possible neurophysiological basis for working memory (Goldman-Rakic, 1996; Wang et al.,

\section{Received Dec. 11, 2013; revised Jan. 15, 2014; accepted Jan. 20, 2014}

Author contributions: B.S. and J.L.B. designed research; C.B., B.S.B., and R.J.G. performed research; J.A.M., C.J.F., and B.S. contributed unpublished reagents/analytic tools; C.B., B.S., and J.L.B. analyzed data; C.B. and J.L.B. wrote the paper.

This work was supported by AG029421 and the McKnight Brain Research Foundation (J.L.B.), and a NSF Graduate Research Fellowship (B.S.B.).We thank Vicky Kelley and Bonnie McLaurin for technical assistance.

The authors declare no competing financial interests.

Correspondence should be addressed to Dr Jennifer L. Bizon, Department of Neuroscience, McKnight Brain Institute, University of Florida, Gainesville, FL 32610-0244. E-mail: bizonj@ufl.edu.

DOI:10.1523/JNEUROSCI.5192-13.2014

Copyright $\odot 2014$ the authors $\quad 0270-6474 / 14 / 343457-10 \$ 15.00 / 0$
2013). In addition, input from a diverse group of GABAergic interneurons onto somatodendritic compartments of pyramidal cells refines spatial and temporal specificity in this system (GoldmanRakic, 1995; Zaitsev et al., 2009). Altered excitability of PFC pyramidal neurons is a central feature of cognitive disorders associated with a wide range of pathological conditions, such as Down syndrome and schizophrenia (Kleschevnikov et al., 2004; Gonzalez-Burgos and Lewis, 2008) and experimentally induced disruption of PFC GABAergic circuits can produce profound impairments in working memory (Kleschevnikov et al., 2004; Enomoto et al., 2011; Murray et al., 2011). A large body of work has implicated changes in PFC monoamine signaling in age-related working memory decline (Goldman-Rakic and Brown, 1981; Arnsten et al., 1994; Moore et al., 2005); however, less attention has been paid to whether disruptions in inhibitory synaptic substrates also contribute to such decline.

$\mathrm{GABA}(\mathrm{B})$ receptors $(\mathrm{GABA}(\mathrm{B}) \mathrm{Rs})$ are G-protein-coupled receptors that are localized presynaptically on GABAergic and glutamatergic terminals where they regulate neurotransmitter release, as well as postsynaptically on dendritic spines and shafts where they contribute to tonic inhibition of pyramidal neurons (Gonzalez-Burgos, 2010; Pinard et al., 2010). Recently, McQuail et al. (2012) reported a marked and regionally specific reduction of $\mathrm{GABA}(\mathrm{B}) \mathrm{R}$ proteins in aged PFC. The impact on cognition of this age-related decline in PFC GABA(B)Rs is not yet known. Notably, however, other evidence from electrophysiological studies con- 
ducted in both rodents and nonhuman primates indicates that PFC pyramidal neurons may be subject to increased inhibitory input in advanced aging (Luebke et al., 2004; Bories et al., 2013). The first goal of the current study was to investigate expression of GABA(B)Rs and other GABAergic signaling proteins in the young and aged medial prefrontal cortex (mPFC), the rodent homolog of the primate dorsolateral prefrontal cortex (Uylings et al., 2003), in relation to performance on a mPFC-dependent delayed response working memory task. The second goal of this study was to determine the effects of pharmacological manipulations of GABA(B)R signaling on working memory performance and, specifically, to determine whether modulation of GABAergic signaling in the MPFC can attenuate working memory deficits that accompany normal aging.

\section{Materials and Methods \\ Subjects}

Young (6-month-old) and aged (22-month-old) male Fischer 344 rats were obtained from the National Institute on Aging colony (Taconic Farms) and housed in the Association for Assessment and Accreditation of Laboratory Animal Care International accredited vivarium facility in the McKnight Brain Institute at University of Florida in accordance with the rules and regulations of the University of Florida Institutional Animal Care and Use Committee and NIH guidelines. The facility was maintained at a consistent $25^{\circ} \mathrm{C}$ with a $12 \mathrm{~h}$ light/dark cycle (lights on at 8:00 A.M.). Rats were maintained under specific pathogen-free conditions and had ad libitum access to food and water at all times except as noted below. A total of 59 rats (young, $n=24$; aged, $n=35$ ) were used in this study. Numbers of rats in each experiment were as follows: Experiment 1: young, $n=6$ and aged, $n=12$; Experiment 2: young, $n=10$ and aged, $n=13$; Experiment 3: young, $n=8$ and aged, $n=10$.

\section{Experiment 1: GABA signaling protein expression and working memory abilities}

The goal of Experiment 1 was to determine the expression of GABAergic signaling proteins in relation to age-related decline on a mPFCdependent delayed response task that assesses working memory.

\section{Delayed response task procedures}

Apparatus. Testing in the delayed response task was conducted in eight identical standard rat behavioral test chambers $(30.5 \times 25.4 \times 30.5 \mathrm{~cm}$, Coulbourn Instruments) with metal front and back walls, transparent Plexiglas side walls, and a floor composed of steel rods $(0.4 \mathrm{~cm}$ diameter) spaced $1.1 \mathrm{~cm}$ apart. Each test chamber was housed in a sound-attenuating cubicle, and was equipped with a recessed food pellet delivery trough located $2 \mathrm{~cm}$ above the floor in the center of the front wall. The trough was fitted with a photobeam to detect head entries and a $1.12 \mathrm{~W}$ lamp for illumination. Food rewards consisted of deliveries of a single $45 \mathrm{mg}$ grain-based food pellet for each correct response (PJAI, Test Diet). Two retractable levers were located to the left and right of the food trough (11 cm above the floor). An additional $1.12 \mathrm{~W}$ house light was mounted near the top of the rear wall of the soundattenuating cubicle. A computer interfaced with the behavioral test chambers and equipped with Graphic State 3.01 software (Coulbourn Instruments) was used to control experiments and collect data.

Shaping. Before the start of behavioral testing, rats were reduced to $85 \%$ of their free-feeding weights over the course of $5 \mathrm{~d}$ and maintained at this weight for the duration of behavioral testing. Rats progressed through three stages of shaping before the onset of the delayed response task, with a new stage beginning on the day immediately following completion of the previous stage. On the day before Shaping Stage 1, each rat was given five $45 \mathrm{mg}$ food pellets in its home cage to reduce neophobia to the food reward used in the task. Shaping Stage 1 consisted of a 64 min session of magazine training, involving 38 deliveries of a single food pellet with an intertrial interval of $100 \pm 40 \mathrm{~s}$. Shaping Stage 2 consisted of lever press training, in which a single lever (left or right, counterbalanced across age groups) was extended and a press resulted in delivery of a single food pellet. After reaching a criterion of 50 lever presses in $30 \mathrm{~min}$, rats were then trained on the opposite lever using the same procedures.

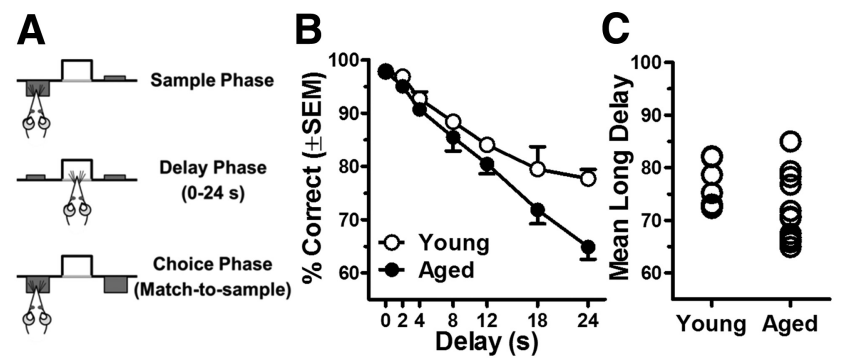

Figure 1. Working memory is impaired in aged Fischer 344 rats. $A$, A schematic of the delayed response task used to assess working memory ability. There are three phases to this task. In the sample phase, rats are presented with either a left or right lever. After the rat presses the extended lever, the delay phase begins. In the delay phase, both levers are retracted for a variable time period ranging from 0 to $24 \mathrm{~s}$, during which the rat must nosepoke into the food trough to initiate the choice phase. In the choice phase, both levers are presented and the rat must press the same lever presented in the sample phase to obtain a food reward. $\boldsymbol{B}$, Young $(n=6)$ and aged $(n=12)$ rats performance on the delayed response task. Aged rats displayed significantly less accurate performance relative to young and were disproportionately impaired at long delays. $\boldsymbol{C}$, Individual young and aged rats plotted by mean long delay (average of choice accuracy at 18-24s) on the delayed response task. This measure was used as an index of individual working memory ability. Error bars represent \pm SEM. See Results for statistical analysis.

During Shaping Stage 3, either the left or right lever (counterbalanced across trials in this Stage of testing) was extended and a press resulted in a single food pellet delivery. Rats were trained in Shaping Stage 3 until achieving 80 lever presses in a 30 min session.

\section{Working memory assessment}

The working memory assessment was based on Sloan et al. (2006), and was used previously to demonstrate age-related impairments in Fischer 344 rats (Beas et al., 2013). Each session was $40 \mathrm{~min}$ in duration, and the house light was illuminated throughout the entire session except during timeout periods (see below). Rats received only a single test session per day. A trial began with the extension of a single lever (the "sample" lever) into the chamber (Fig. 1). The left/right position of this lever was randomly selected within each pair of trials, and a lever press caused it to retract and started the delay period timer. During the delay, rats were required to nosepoke into the food trough to initiate the "choice" phase, and the first such nosepoke emitted after the delay timer expired caused both levers to extend. During this choice phase, a response on the same lever pressed during the sample phase (a correct response) resulted in both levers being retracted and delivery of a single food pellet. Entry into the food trough to collect the food pellet initiated a $5 \mathrm{~s}$ intertrial interval, after which the next trial was initiated. A response on the opposite lever from that chosen during the sample phase (an incorrect response) resulted in both levers being retracted and initiation of a $5 \mathrm{~s}$ "timeout" period during which the house light was extinguished, followed immediately by the start of the next trial.

During initial sessions in this task, there were no delays between the sample and choice phases, and a correction procedure was used such that the sample lever was repeated on the same side following an incorrect response to prevent development of side biases. Once rats reached a criterion of $80 \%$ correct choices across a session for two consecutive sessions, this correction procedure was discontinued and a set of seven delays was introduced. The presentation of delay durations was randomized within each block of seven trials, such that each delay was presented once within a block. Upon establishing $>80 \%$ correct performance across two consecutive sessions in a Set, rats were progressed to the next Set (Set 1: 0, 1, 2, 3, 4, 5, 6 s; Set 2: 0, 2, 4, 8, 12, 16 s; Set 3: 0, 2, 4, 8, 12, 18, and $24 \mathrm{~s})$. Rats were tested for five consecutive sessions on the delays in Set 3 to acquire baseline performance data.

Approximately 2 weeks after completion of behavioral testing and return to ad libitum food, rats were decapitated and brains were removed from the skull, cooled on ice, and sliced in $1 \mathrm{~mm}$ coronal sections using a rat brain matrix. Coronal sections were placed on an ice-cold plate, and the $\mathrm{mPFC}$ was dissected and stored at $-80^{\circ} \mathrm{C}$ until use. At the rostrocau- 
dal coordinates of Paxinos and Watson (AP: +3.7 through +2.2$)$, the boundaries of the mPFC were delineated dorsally and medially by the emergence of the white matter tracts surrounding the striatum, and ventrally by the ventral tip of the corpus collosum. As cognitive task performance can elicit changes in protein expression (Davis et al., 1996; Wass et al., 2013), this 2 week post-training interval was selected to evaluate baseline rather than behaviorally stimulated protein levels. Western blot analysis performed on homogenates generated from these dissected tissue samples was used to evaluate the influence of age and cognitive performance on the following GABAergic signaling proteins: the GABA(B) receptor $\mathrm{R} 1 \mathrm{a}, \mathrm{R} 1 \mathrm{~b}$, and $\mathrm{R} 2$ subunits, the primarily neuronal GABA transporter GAT-1, the GABA synthesizing enzyme GAD67, and the vesicular GABA transporter VGAT.

\section{Western blotting procedures}

Sample preparation. Frozen tissue was weighed, thawed, and homogenized in 10 volumes of an ice-cold buffer (50 mm 4-(2-Hydroxyethyl) piperazine-1-ethanesulfonic acid, $N$-(2-Hydroxyethyl)piperazine- $N^{\prime}$ (2-ethanesulfonic acid) (HEPES), $\mathrm{pH} 7.4,1 \mathrm{~mm}$ ethylenediaminetetraacetic acid and $1 \mathrm{~mm}$ ethylene glycol-bis(2-aminoethylether)-N,N,N', $\mathrm{N}^{\prime}$-tetraacetic acid and protease inhibitors; Roche) using a glass-Teflon Dounce homogenizer. Homogenates were centrifuged at 14,000 rpm for 20 $\min$ at $4^{\circ} \mathrm{C}$. The supernatant was collected and stored in aliquots for Western blotting assays of nonmembrane-bound proteins. The pellet was resuspended in $20 \mathrm{ml}$ of the same buffer without protease inhibitors and incubated on ice for $30 \mathrm{~min}$ followed by centrifugation at 16,500 rpm for $15 \mathrm{~min}$ at $4^{\circ} \mathrm{C}$. This pellet was resuspended in 10 volumes of $50 \mathrm{~mm}$ HEPES, $\mathrm{pH} 7.4$, and aliquots were stored at $-80^{\circ} \mathrm{C}$ until used for Western blotting assays. Protein concentration was determined using the Pierce BCA Kit according to the manufacturer's protocol.

Immunoblotting. Proteins were denatured and reduced in Laemmli sample buffer with $5 \%(\mathrm{v} / \mathrm{v}) \beta$-mercaptoethanol (Fisher) and heated at $95^{\circ} \mathrm{C}$ for $5 \mathrm{~min}$. Initial experiments focused on evaluating expression of PFC GABA(B)R1 and GABA(B)R2 subunits as well as GAT-1. Subsequently, and to the extent possible, expression of GAD67 and VGAT were assessed in this same cohort. The GABA(B)R1 and GABA(B)R2, GAT-1, and VGAT assays were conducted using the membrane preparation, whereas the GAD67 assay was conducted using the supernatant fraction collected as described above. Note that the supernatant was not available for all subjects and therefore only a subset of young and aged rats were included in the GAD67 study (young, $n=6$; aged, $n=7$ ). Similarly, for some animals, there was no remaining membrane homogenate available for use in the VGAT study, resulting in fewer animals included in this study (young, $n=6$ young; aged, $n=8$ ). In all Western blot experiments, 10 micrograms of protein per lane were electrophoretically separated on a $4-15 \%$ Tris- $\mathrm{HCl}$ gel at $200 \mathrm{~V}$ for $35 \mathrm{~min}$ then transferred to nitrocellulose membranes using a wet transfer apparatus for $90 \mathrm{~min}$ at $0.35 \mathrm{~A}$. Blots were washed 3 times with tris-buffered saline (TBS; pH 7.4) then blocked for $1 \mathrm{~h}$ in blocking buffer (Rockland). Blots were then incubated overnight at $4^{\circ} \mathrm{C}$ with antibodies (anti-GAD67, Millipore; anti-GAT-1, Millipore; anti-VGAT, Millipore; anti-GABA(B)R1, Cell Signaling Technology; anti-GABA(B)R2, Cell Signaling Technology) diluted 1:1000 in blocking buffer (Rockland) with $0.1 \%$ Tween 20 (Bio-Rad). Blots were then washed three times with $0.1 \mathrm{M}$ TBS and incubated with the appropriate AlexaFluor 680-conjugated anti-IgG (Invitrogen) diluted 1:20,000 in TBS with $0.1 \%$ Tween 20 (Bio-Rad) for $1 \mathrm{~h}$. Following three additional TBS washes, blots were scanned on an Odyssey imaging system (LI-COR Biosciences).

\section{Statistical analyses}

Raw data files generated from delayed response test sessions were exported from Graphic State software and compiled using a custom macro written for Microsoft Excel (Dr Jonathan Lifshitz, University of Kentucky). To assess working memory abilities, mean accuracy (percentage correct responses) at each delay across five test sessions performed at the final set of delays (Set 3) was calculated and age comparisons were conducted using two-factor repeated-measure ANOVA (age $\times$ delay). For Western blot analyses, integrated protein density was measured for each band and the individual values of both young and aged samples were normalized to the mean expression of young samples run on the same gel. Age comparisons of protein expression were conducted using independent $t$ tests. Note that each blot was probed separately for glyceraldehyde 3-phosphate dehydrogenase (GAPDH) expression to confirm that age effects were not a result of nonspecific effects of loading or quantification of protein content. In no cases were age comparisons performed on GAPDH measures significant (GAPDH on R1a and R1b blot: $t_{(16)}=$ $0.34, p=0.74$; GAPDH on GABA(B)R2 blot: $t_{(16)}=-0.98, p=0.35$; GAPDH on GAT-1 blot: $t_{(16)}=0.49, p=0.63$; GAPDH on GAD67 blot: $\left.t_{(11)}=-0.10, p=0.34\right)$. To directly test relationships between changes in protein expression and working memory abilities among aged rats, mean percentage accuracy averaged across the two longest delays (18 and $24 \mathrm{~s}$ ) was calculated for each subject and this "mean long delay" performance measure was used as an index of working memory ability. Relationships between expression of each protein of interest and mean long delay performance were tested using Pearson's correlations. For this and all subsequent experiments, data are presented as the mean \pm SEM. All statistical analyses were conducted using SPSS 21.0 and GraphPadPrism. For all statistical comparisons, values of $p<0.05$ were considered significant.

\section{Experiment 2: Systemic administration of the GABA(B) receptor antagonist CGP55845}

This experiment was designed to test the hypothesis that blockade of GABA(B)Rs via systemic administration of the selective antagonist CGP55845 can improve working memory performance in aged rats.

\section{Drug administration procedures}

Rats were trained on the delayed response task as described above for Experiment 1. Pharmacological testing began on the day after establishing baseline performance measures (i.e., after completing 5 sessions of testing on the longest set, Set 3, of delays). Rats received intraperitoneal $(1.0 \mathrm{ml} / \mathrm{kg})$ injections of the selective GABA(B)R antagonist CGP55845 $(0.01$ or $0.1 \mathrm{mg} / \mathrm{kg}$; Tocris Bioscience) or $0.9 \%$ saline vehicle $40 \mathrm{~min}$ before testing. The choice of this drug and dose regimen was based on several previous studies in which systemic administration of CGP55845 was shown to exert behavioral effects in rodents. Froestl et al. (1996), showed that CGP55845 reversed baclofen-induced hypothermia, supporting in vivo actions at $\mathrm{GABA}(\mathrm{B})$ receptors. Moreover, previous work from our lab and others has shown that intraperitoneal administration of CGP55845 can exert cognitive benefits in a mouse model of Down syndrome as well as in aged rats (Kleschevnikov et al., 2012, LaSarge et al., 2009). Drugs were administered in a randomized, counterbalanced order such that each rat was tested under each drug condition. A $48 \mathrm{~h}$ washout period was interposed between injections, during which delayed response testing was conducted in the absence of drug administration.

\section{Data analyses}

Analysis of baseline performance in the delayed response task was calculated as described above in Experiment 1. The effects of GABA(B)R antagonist administration were assessed using a three-factor repeatedmeasures ANOVA, with both drug dose and delay as repeated measures variables and age as a between-subjects variable. Post hoc comparisons within each age group were performed using two-factor repeated ANOVAs (drug dose $\times$ delay). When justified, additional two-factor ANOVAs were used to compare individual drug doses against vehicle conditions within each age group to determine those doses that significantly altered performance.

\section{Experiment 3: Intracerebral microinjections of the GABA(B) receptor antagonist CGP55845}

This experiment was designed to test the hypothesis that the mPFC is a critical site of action for the cognitively enhancing effects of the selective GABA(B)R antagonist CGP55845.

\section{Cannulation surgery}

Young and aged rats were anesthetized with isofluorane gas and fixed into a stereotaxic frame (Kopf Instruments) fitted with atraumatic earbars. The incisor bar was set at $-3.3 \mathrm{~mm}$ relative to the interaural line to 
provide a flat skull position. Bilateral guide cannulae, which consisted of a plastic body holding two 22-gauge stainless steel cannulae $1.4 \mathrm{~mm}$ apart (Plastics One), were implanted to target mPFC (AP: +1.7 relative to bregma, ML: $\pm 0.7, \mathrm{DV}:-3.8$ relative to skull). Cannulae were secured to the skull with dental acrylic and stainless steel screws, and wire stylets were used to occlude the guide cannulae to prevent infection.

\section{Intracerebral microinjections of the $G A B A(B)$ receptor} antagonist CGP55845

Following a 2 week recovery period, rats were trained in the delayed response task until they completed five sessions at the longest set of delays as in Experiments 1 and 2. On the next day, rats received a dummy injection during which the stylets were removed from the guide cannulae and injectors ( 28 gauge needles which extended $1.0 \mathrm{~mm}$ beyond the end of the guide cannulae; Plastics One) were lowered into the mPFC. This dummy injection (in which no drug was injected) served to acclimate the rat to the handling necessary to administer the drug. In subsequent test sessions, rats received bilateral microinjections of the GABA(B)R antagonist CGP55845 $(0.2,0.6$, and $2.0 \mu \mathrm{mol})$ or vehicle (artificial CSF, Harvard Apparatus) using a randomized, counterbalanced design such that each rat was tested in each drug condition. Microinjections $(0.5 \mu \mathrm{l}$ per hemisphere, given over the course of $60 \mathrm{~s}$ ) were administered $5 \mathrm{~min}$ before the start of delayed response test sessions. Microinjections were delivered via $10 \mu \mathrm{l}$ syringes connected to the injection needles by a length of PE-20 tubing. These parameters were chosen based on previous work showing that drug microinjections of this volume into mPFC produce reliable and specific effects on $\mathrm{mPFC}$-dependent cognitive tasks including working memory, with minimal diffusion to the midline or ventricles (Taylor et al., 1999; Ragozzino, 2002; Stefani and Moghaddam, 2005; Allen et al., 2008; St Onge et al., 2011). The syringes were mounted on a syringe pump (Pump 11 Elite, Harvard Apparatus) and needles were left in place for $1 \mathrm{~min}$ after injections to allow for drug diffusion. A $48 \mathrm{~h}$ washout period was interposed between drug injection sessions, during which delayed response testing was conducted in the absence of drug. Performance on these nondrug washout days was monitored for residual effects of the microinjections.

\section{Histological assessment of cannulae placement}

Following completion of testing, rats were killed with $100 \mathrm{mg} / \mathrm{kg}$ sodium pentobarbital, then perfused with $0.1 \mathrm{~m}$ phosphate buffer solution (PBS) followed by $4 \%$ paraformaldehyde in $0.1 \mathrm{~m}$ PBS. Brains were removed and postfixed in $4 \%$ paraformaldehyde overnight and then cryoprotected in 20\% sucrose in PBS. Brains were then flash frozen and sliced coronally at 50 micrometers on a cryostat (Leica Jung Frigocut 2800E). Every other tissue slice was thionin-stained and visualized using a microscope under conventional bright-field illumination. Cannula tip placements were verified and mapped onto standardized coronal sections of the rat brain (Paxinos and Watson, 2005).

\section{Data analyses}

Baseline working memory performance of young and aged rats in this cohort was assessed using a two-factor repeated-measure ANOVA (age $\times$ delay) as in Experiments 1 and 2. The effects of drug manipulations were assessed using three-factor repeated-measures ANOVA as in Experiment 2, with both drug dose and delay as repeated measures variables and age as a between-subjects variable. Post hoc comparisons within each age group were performed using two-factor repeated-measures ANOVAs (drug dose $\times$ delay). When justified, additional two-factor ANOVAs were used to compare individual drug doses against vehicle within each age group to determine those doses that significantly affected performance.

\section{Results}

\section{Experiment 1: GABA signaling protein expression and working memory abilities}

Working memory performance is impaired in aged F344 rats

To relate age-related changes in GABAergic signaling protein expression to $\mathrm{mPFC}$-dependent cognitive abilities, young and aged rats were characterized on a delayed response task that assesses working memory (Fig. 1A, task schematic). Previous work has shown that performance on this task critically depends upon the $\mathrm{mPFC}$ and that aged rats are impaired relative to young cohorts (Sloan et al., 2006; Beas et al., 2013). Delayed response performance of young and aged rats is shown in Figure $1 B$. Consistent with previous findings, a two-factor repeated-measures ANOVA (age $X$ delay) indicated that both young and aged rats showed reduced accuracy as delays increased (main effect of delay: $\left.F_{(6,96)}=65.69, p<0.001\right)$. Notably, however, aged rats performed significantly worse than young cohorts (main effect of age: $F_{(1,16)}=7.07, p=0.02$ ), and this impairment was disproportionately evident at long delays (interaction between delay and age: $\left.F_{(6,96)}=3.14, p=0.01\right)$. Given that the greatest magnitude age-related deficits occurred at the longest two delays tested (i.e., 18 and 24 s), performance at these delays was averaged for each subject and this value (mean long delay) was used as an index of individual working memory ability. Figure $1 C$ shows the mean long delay performance for individual young and aged rats.

\section{Age-related alterations in GABAergic signaling protein expression} in aged $M P F C$

Figure $2 A$ shows representative immunoreactive bands from young and aged $\mathrm{mPFC}$ samples when incubated with antibodies to $\mathrm{GABA}(\mathrm{B})$ receptor $\mathrm{R} 1$ or R2 subunits, GAT-1, GAD67, or VGAT. As GABA(B)Rs are obligate heterodimers and functional receptors require at least one $\mathrm{GABA}(\mathrm{B}) \mathrm{R} 1$ subunit with one GABA(B)R2 subunit (Jones et al., 1998; Kaupmann et al., 1998; White et al., 1998), mPFC expression of both R1 and R2 subunits was assessed. In addition, note that two distinct bands were detected for GABA(B)R1 (130 kDa and $95 \mathrm{kDa})$, corresponding to the two different isoforms of this subunit: GABA(B)R1a and GABA(B)R1b, respectively (Kaupmann et al., 1997). The GABA(B)R1a isoform contains a pair of short consensus repeats at the $\mathrm{N}$-terminal that traffick GABA(B)R complexes containing this isoform to presynaptic terminals where these receptors modulate neurotransmitter release (Biermann et al., 2010). Conversely, GABA(B)R1b lacks this N-terminal extension and is primarily localized to dendrites where it mediates postsynaptic inhibition (Vigot et al., 2006). Given the distinct localization and function of these R1 isoforms, R1a and R1b were analyzed separately. In agreement with previous work from our laboratory (McQuail et al., 2012), expression of both R1 isoforms and of the $\mathrm{R} 2$ subunit were robustly and significantly reduced in aged compared with young $\mathrm{mPFC}\left(\mathrm{R} 1 \mathrm{a}:-29 \%, t_{(16)}=2.80, p=0.01\right.$; Fig. $2 B$; R1b: $-42 \%, t_{(16)}=3.42, p=0.003$; Figure $2 C$; and GABA(B)R2: $-28 \%, t_{(16)}=2.67, p=0.02$; Figure $\left.2 D\right)$. In addition, bivariate correlation analyses were performed on individual data from aged rats to compare the expression of each GABA(B)R isoform and subunit to individual performance on the delayed response task. As shown in Figure $2 B$, expression of the $\mathrm{GABA}(\mathrm{B}) \mathrm{R} 1 \mathrm{a}$ isoform in aged rats was not significantly associated with mean long delay performance (R1a: $r=-0.48, p=$ 0.12 ; Fig. $2 B$ ). In contrast to R1a, expression of both R1b and R2 in aged rats was significantly and negatively associated with mean long delay performance (R1b: $r=-0.66, p=0.02$; Fig. $2 C$; R2: $r=-0.75, p=0.01$; Fig. $2 D)$, such that lower expression was associated with better performance on the working memory task. Bivariate correlation analyses were also performed separately on data from young rats and in no cases were significant relationships observed between individual GABA(B)R subunit expression and mean long delay performance (R1a: $r=-0.12$, $p=0.82$; R1b: $r=0.28, p=0.60$; R2: $r=-0.03, p=0.96)$.

The primary neuronal GABA transporter, GAT-1 has been strongly implicated in GABA(B)R occupancy (Gonzalez-Burgos 

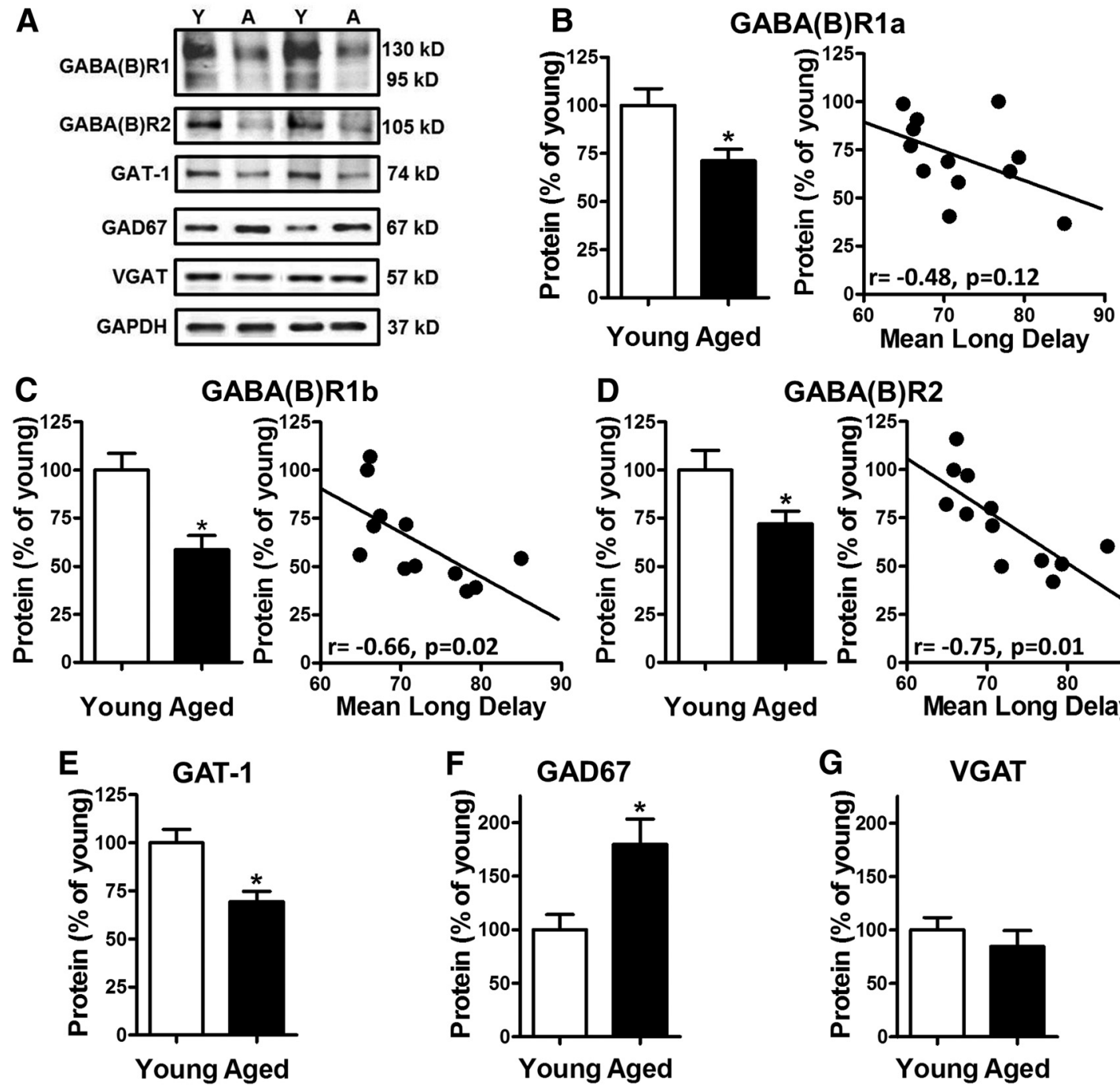

Figure 2. Age-related changes in GABAergic signaling protein expression and relationship with working memory ability. $A$, Representative immunoreactive bands from young ( $n=6$ ) and aged $(n=12) \mathrm{mPFC}$ homogenates following incubation with antibodies to the GABA(B)R subunits R1 and R2, the GABA transporter GAT-1, the GABA synthesizing enzyme GAD67, the vesicular GABA transporter VGAT and loading control GAPDH. $B$, In the aged $\mathrm{mPFC}, \mathrm{GABA}(\mathrm{B}) \mathrm{R} 1$ a expression was significantly reduced compared with young; however, as shown in the scatter plot of individual aged rats, there was no significant relationship between $G A B A(B) R 1$ a expression and delayed response performance. $C$, Expression of GABA(B)R1b was significantly reduced in aged mPFC compared with young. The scatter plot of individual aged rats shows that, in contrast to $G A B A(B) R 1 a, G A B A(B) R 1 b$ expression was significantly and inversely associated with delayed response performance such that lower expression was associated with better working memory ability. D, GABA(B)R2 expression was also significantly reduced in aged mPFC compared with young. Like the R1b isoform, the scatter plot of protein expression of individual aged rats shows that GABA(B)R2 expression in the $\mathrm{mPFC}$ is significantly and inversely related to working memory performance such that those aged rats with the lowest levels of GABA(B)R2 exhibited better working memory. $\boldsymbol{E}$, Expression of GAT-1 was significantly decreased in aged mPFC compared with young. $\boldsymbol{F}$, In contrast to all other signaling proteins examined, expression of GAD67, was significantly elevated in aged mPFC compared with young. Neither GAT-1 nor GAD67 expression in mPFC was reliably related to working memory performance. G, Notably, expression of VGAT did not differ between young and aged mPFC, suggesting that aging does not produce a robust loss of inhibitory terminals in this brain region. Error bars represent \pm SEM. See Results for statistical analyses. Asterisks indicate significant differences $(p<0.05)$.

et al., 2009), and therefore expression of GAT-1 was also evaluated in the same membrane homogenates. Similar to GABA(B)R expression, GAT-1 was significantly reduced in aged compared with young $\mathrm{mPFC}\left(-31 \%, t_{(16)}=3.82, p=0.002\right.$; Fig. $\left.2 E\right)$. Notably, however, no significant relationship was observed between GAT-1 expression and mean long delay performance in aged rats (GAT-1: $r=-0.30, p=0.34$ ). Likewise, there was no significant relationship between GAT-1 expression and working memory abilities among young rats (GAT-1: $r=-0.42, p=$ $0.15)$.

Given the marked reduction of GABA(B)Rs and GAT-1 expression in aged $\mathrm{mPFC}$ described above, subsequent experiments were performed to provide additional information regarding how aging influences inhibitory synapses in this brain region.
Specifically, expression of the GABA synthesizing enzyme, GAD67, and of the vesicular transporter for GABA, VGAT, was evaluated in the mPFC of young and aged rats. As shown in Figure 2F, GAD67 expression was robustly and significantly elevated in aged mPFC compared with young (GAD67: $+80 \%$, $\left.t_{(11)}=-2.80, p=0.02\right)$. In contrast, VGAT expression in mPFC did not differ between young and aged rats (VGAT: $t_{(12)}=1.03$, $p=0.33$; Fig. $2 G$ ). As described in Materials and Methods, tissue from only a subset of the rats was available for GAD67 and VGAT immunoblots. Analysis of delayed response performance of the rats included in these assays revealed the same working memory impairment in aged rats compared with young that was observed in the larger cohort (In the behavioral cohort used to assess GAD67 expression, there was a main effect of delay: $F_{(6,66)}=$ 
68.31, $p<0.001$; a main effect of age: $F_{(1,11)}=7.27, p=0.02$; and an interaction between delay and age: $F_{(6,66)}=4.68, p=$ 0.001 . In the behavioral cohort used to assess VGAT expression, there was a main effect of delay: $F_{(6,72)}=99.51, p<0.001$; a main effect of age: and an $F_{(1,12)}=7.08$, $p=0.02$; and an interaction between delay and age: $\left.F_{(6,66)}=5.08, p<0.001\right)$. Notably, no significant relationships were observed between GAD67 or VGAT expression in $\mathrm{mPFC}$ and mean long delay performance in the working memory assessment among aged (VGAT-1: $r=-0.34$, $p=0.40$; GAD67: $r=0.22, p=0.64$ ) or young (VGAT: $r=-0.30, p=0.47$; GAD67: $r=-0.30, p=0.56)$ rats.

Experiment 2: Systemic administration of the selective GABA(B)R antagonist CGP55845 restores working memory performance in aged rats

Data from Experiment 1 show that expression of GABAergic signaling proteins is altered in aged $\mathrm{MPFC}$ in a manner that is consistent with increased inhibition of cortical pyramidal neurons (Luebke et al., 2004; Bories et al., 2013). Moreover, reduced expression of postsynaptic GABA(B)Rs (GABA(B)R1b and $\mathrm{GABA}(\mathrm{B}) \mathrm{R} 2$ subunits) is significantly associated with better performance on the delayed response task. Together, these data support the hypothesis that reducing $\mathrm{GABA}(\mathrm{B}) \mathrm{R}$ activity should improve working memory performance in aged rats. To test this hypothesis, performance of young and aged rats was evaluated in the delayed response task following systemic administration of the selective GABA(B)R antagonist CGP55845 or vehicle. Baseline performance before drug administration, shown in Figure $3 A$, was similar to that observed in Experiment 1. A two factor ANOVA (age $\times$ delay) indicated that both young and aged rats performed less accurately at longer delays (main effect of delay: $F_{(6,126)}=110.72, p<0.001$ ) and that aged rats performed significantly worse than young rats (main effect of Age: $F_{(1,21)}=9.23, p=0.006$; Fig. $3 A$ ), particularly at longer delays (interaction between delay and age: $F_{(6,126)}=3.94, p=0.04$ ).

With respect to the effects of $\mathrm{GABA}(\mathrm{B}) \mathrm{R}$ blockade, a three factor ANOVA (age $\times$ delay $\times$ drug dose) revealed main effects of delay $\left(F_{(6,252)}=89.53, p<0.001\right)$ and drug dose $\left(F_{(2,42)}=\right.$ 3.64, $p=0.04)$, as well as a significant interaction between age and drug dose $\left(F_{(2,42)}=7.42, p=0.002\right)$. No other main effects or interactions were statistically significant. To better understand the nature of the interaction between age and the effects of the GABA(B)R antagonist on delayed response performance, two factor ANOVAs (drug dose $\times$ delay) were performed separately in young and aged rats. Among aged rats, there were significant main effects of delay $\left(F_{(6,72)}=98.46, p<0.001\right)$ and drug dose $\left(F_{(2,24)}=7.81, p=0.002\right)$ but no interaction between these two variables. Given the main effect of drug dose, subsequent post hoc analyses were performed to individually compare the two doses of $\operatorname{GABA}(\mathrm{B}) \mathrm{R}$ antagonist to vehicle and to each other. These comparisons showed that in aged rats, $0.1 \mathrm{mg} / \mathrm{kg}\left(F_{(1,12)}=16.89\right.$, $p=0.001)$, but not $0.01 \mathrm{mg} / \mathrm{kg}$ CGP55845 $\left(F_{(1,12)}=0.93, p=\right.$ $0.35)$, significantly enhanced performance relative to the vehicle condition (Fig. $3 B$ ). The $0.1 \mathrm{mg} / \mathrm{kg}$ dose also significantly enhanced performance relative to the $0.01 \mathrm{mg} / \mathrm{kg}$ dose $\left(F_{(1,12)}=\right.$ $6.76, p=0.02)$. In contrast to the enhancing effects of GABA(B)R antagonist administration in aged rats, systemic administration
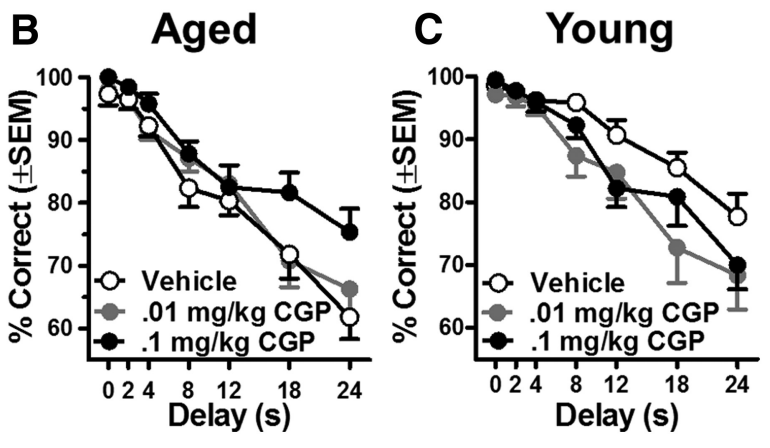

Figure 3. Systemic $\mathrm{GABA}(\mathrm{B})$ receptor antagonist administration significantly improves working memory performance in aged rats. $\boldsymbol{A}$, Baseline performance on the delayed response task of young $(n=10)$ and aged $(n=13)$ rats before drug administration. Aged rats displayed significantly less accurate performance relative to young and were disproportionately impaired at long delays. effects observed in aged rats, systemic injection of CGP55845 (shaded circles) significantly impaired working memory performance (e conditions (open circles). Error bars represent \pm SEM. See Results for statistical analyses.

of CGP5545 impaired working memory performance in young rats. A two-factor ANOVA (drug dose $\times$ delay) revealed main effects of delay $\left(F_{(6,54)}=41.48, p<0.001\right)$ and drug dose $\left(F_{(2,18)}=3.93, p=0.04\right)$, but no interaction between these two variables. Post hoc comparisons showed that the $0.01 \mathrm{mg} / \mathrm{kg}$ $\left(F_{(1,9)}=7.17, p=0.025\right)$ but not the $0.1 \mathrm{mg} / \mathrm{kg}$ dose $\left(F_{(1,9)}=\right.$ $3.06, p=0.11)$ significantly impaired working memory performance of young rats compared with vehicle conditions. There was no significant difference in performance between the 0.1 $\mathrm{mg} / \mathrm{kg}$ and the $0.01 \mathrm{mg} / \mathrm{kg}$ doses $\left(F_{(1,9)}=1.25, p=0.29\right)$.

\section{Experiment 3: Intra-mPFC infusions of the selective GABA(B) receptor antagonist CGP55845 restores working memory performance in aged rats}

Data from Experiment 2 demonstrate that blocking GABA(B)Rs via systemic administration of CGP55845 significantly improves working memory performance in aged rats. To determine whether these effects were mediated by actions in mPFC, young and aged rats were implanted with guide cannulae targeting mPFC. Figure $4 A$ shows the location of cannula placements for rats used in this study. Figure $4 B$ shows predrug baseline performance of these young and aged rats before drug microinjections. A two-factor ANOVA (age $\times$ delay) indicated that both young and aged rats performed less accurately at longer delays (main effect of delay: $F_{(6,96)}=76.84, p<0.001$ ) and that aged rats performed significantly worse than young rats (main effect of age: $F_{(1,16)}=7.66, p=0.02$; Fig. $\left.3 B\right)$.

With respect to the effects of $\mathrm{mPFC}$ GABA(B)R blockade, a three factor ANOVA (age $\times$ delay $\times$ drug dose) revealed a main effect of delay $\left(F_{(6,96)}=104.94, p<0.001\right)$ and significant interactions between age and delay $\left(F_{(6,96)}=3.15, p=0.007\right)$ and age $\times$ drug dose $\left(F_{(3,48)}=2.92, p=0.04\right)$. No other main effects or interactions were observed. To better understand the nature of the interaction between age and the effects of mPFC GABA(B)R blockade on delayed response performance, two-factor ANOVAs (drug dose $\times$ delay) were performed separately in young and aged rats. Among aged rats, there were main effects of drug dose $\left(F_{(3,27)}=3.16, p=0.04\right)$ and delay $\left(F_{(6,54)}=75.52, p<0.001\right)$ but no interaction between these variables. Post hoc ANOVAs comparing each dose with vehicle and each other indicated that the $0.6 \mu \mathrm{mol}$ dose of CGP55845 $\left(F_{(1,9)}=6.25, p=0.03\right)$, but not the $0.2 \mu \mathrm{mol}\left(F_{(1,9)}=0.29, p=0.61\right)$ or $2.0 \mu \mathrm{mol}\left(F_{(1,9)}=0.81\right.$, 

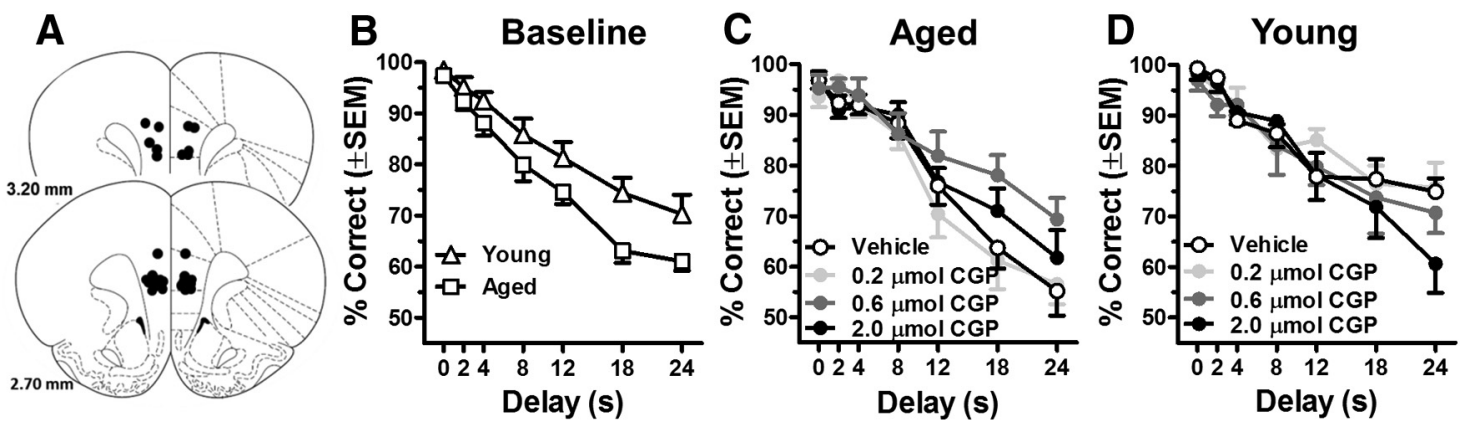

Figure 4. Intra-mPFC GABA(B) receptor antagonist administration improves working memory performance in aged rats. $A$, shows bilateral cannula placements in $\mathrm{mPFC}$ for each rat included in this experiment (schematic illustrations modified from Paxinos and Watson, 2005). B, Baseline delayed response task performance of young $(n=8)$ and aged ( $n=10)$ rats before drug administration. Aged rats displayed significantly less accurate performance relative to young. C, Direct mPFC administration of the selective GABA(B)R antagonist CGP55845 (shaded circles) significantly enhanced working memory performance in aged rats over vehicle conditions (open circles). Note that administration of the $0.6 \mu$ mol dose (dark gray circles), improved accuracy of aged rats to a level on par with young baseline performance (open triangles in $\boldsymbol{B}$ ). $\boldsymbol{D}$, In contrast to drug effects observed in aged rats, direct mPFC administration of (GP55845 (shaded circles) did not significantly affect working memory performance of young rats compared with vehicle conditions (open circles). Error bars represent \pm SEM. See Results for statistical analyses.

$p=0.37)$ doses, significantly improved working memory performance relative to vehicle conditions (Fig. 3C). Furthermore, performance at the $0.6 \mu \mathrm{mol}$ dose of CGP55845 was significantly better compared with the $0.2 \mu \mathrm{mol}$ dose $\left(F_{(1,9)}=6.83, p=0.03\right)$, whereas no other dose comparisons yielded significant differences in performance $\left(0.2 \mu \mathrm{mol}\right.$ vs $2.0 \mu \mathrm{mol}: F_{(1,9)}=4.07, p=$ 0.07; $0.6 \mu \mathrm{mol}$ vs $\left.2.0 \mu \mathrm{mol}: F_{(1,9)}=61.45, p=0.26\right)$. Performance on the nondrug days that intervened between drug microinjection days was also monitored to assess nonspecific effects on performance of repeated mPFC microinjections. A two-factor (day $\times$ delay) ANOVA performed on aged rats' data from these intervening days indicated the expected main effect of delay $\left.F_{(6,54)}=58.52, p<0.001\right)$, but no main effect of day $\left(F_{(4,36)}=\right.$ $1.44, p=0.24)$ nor a day $\times$ delay interaction $\left(F_{(24,216)}=0.99, p=\right.$ 0.48 ), indicating that there were no adverse effects on performance of repeated mPFC microinjections.

In contrast to aged rats, a two factor (delay $\times$ drug dose) ANOVA performed on data from young rats revealed a main effect of delay $\left(F_{(6,42)}=1.31, p=0.18\right)$ but no main effect or interaction involving drug dose.

\section{Discussion}

Working memory, or the ability to hold task-relevant information in mind, is a foundational aspect of cognition that is vulnerable to decline with normal aging. Persistent activity of PFC pyramidal neurons is a central feature of most neural models of working memory, and input to these neurons from diverse classes of GABAergic interneurons is considered essential for providing spatial and temporal specificity in the encoding and maintenance of to-be-remembered information (Goldman-Rakic, 1995; Arnsten, 2013). Data presented in the current study demonstrate that GABAergic signaling proteins in rat mPFC become dysregulated in normal aging, and suggest that these changes contribute to increased pyramidal neuronal inhibition and a reduced ability to maintain information in working memory stores. In direct support of this idea, we demonstrate that reducing inhibition via GABA(B)R antagonist administration both systemically and directly within $\mathrm{mPFC}$ can significantly enhance working memory performance in aged rats to a level on par with young adult cohorts.

\section{Increased inhibition in aged prefrontal cortex}

Electrophysiological recordings from PFC in both rodents and nonhuman primates indicate that inhibitory input onto PFC py- ramidal neurons can increase with aging (Luebke et al., 2004; Bories et al., 2013). One previous study described a reduction in excitatory postsynaptic spontaneous currents (PSCs) coupled with an increase in inhibitory PSCs onto layer II/III pyramidal neurons in aged nonhuman primate PFC compared with young (Luebke et al., 2004). More recently, Bories et al. (2013) reported that miniature IPSPs onto mPFC pyramidal neurons were increased in aged rats that were impaired on a corner exploration behavioral task. The biochemical data presented in the current study provide further evidence for an age-related increase in the inhibition of mPFC pyramidal neurons. First, the increase in GAD67, the rate-limiting enzyme for GABA synthesis, suggests that there is elevated GABA production in aged mPFC. Second, the R1a isoform of the GABA(B)R, which is localized to presynaptic terminals and negatively regulates neurotransmitter release, was significantly reduced in aged PFC. Loss of the GABA(B)R on inhibitory terminals would be expected to attenuate autoinhibition of GABA release. Finally, GAT-1 expression was significantly reduced in aged mPFC. GAT-1 plays an integral role in clearing GABA from the synapse by translocating GABA through the neuronal membrane. Several studies have localized GAT-1 extrasynaptically on presynaptic terminals (Minelli et al., 1995; Conti et al., 2004), where it has been suggested to play an important role in preventing synaptic GABA spillover and maintaining GABA homeostasis. Electrophysiological data from studies in which GAT-1 is selectively blocked or genetically deleted clearly indicate that reduced GAT-1 expression results in an increase in extracellular GABA concentrations (Frahm et al., 2001; Jensen et al., 2003; Chiu et al., 2005; Gonzalez-Burgos et al., 2009). Together, this constellation of biochemical alterations would be expected to produce increased GABAergic inhibition of pyramidal cells in aged PFC.

Against the background of these changes, postsynaptic GABA(B)R subunit expression was robustly attenuated in aged PFC. This finding agrees with a previous study from our laboratory in which expression of both $\mathrm{R} 1$ and $\mathrm{R} 2$ subunits of the GABA(B)R was reduced in aged PFC (McQuail et al., 2012). Although rats were not characterized on a PFC-dependent behavioral task in that prior study, findings herein show that attenuated $\mathrm{GABA}(\mathrm{B}) \mathrm{R}$ expression is significantly and inversely related to mPFC-dependent working memory. Notably, this relationship was only observed with the GABA(B)R2 subunit and the postsynaptic $\mathrm{GABA}(\mathrm{B}) \mathrm{R} 1 \mathrm{~b}$ isoform of the R1 subunit, but not with the 
presynaptic R1a isoform of the R1 subunit. Postsynaptic GABA(B) receptors are largely located extra-synaptically and are sensitive to alterations in tonic GABA and GABA spillover from active synapses (Kulik et al., 2003, 2006; Glykys and Mody, 2007). Indeed, previous work by Wang et al. (2010) has indicated that GABA(B) receptors mediate a small tonic inhibitory current in layer $2 / 3 \mathrm{mPFC}$ pyramidal neurons in young rats. The data presented here support a model in which interneuron dysfunction in aging contributes to elevated GABA availability and increased GABA(B) mediated tonic activity in aging. In this context, the downregulation of GABA(B)Rs may reflect an effective compensatory mechanism for preserving optimal neuronal excitability and working memory abilities.

\section{$\mathrm{GABA}(\mathrm{B})$ receptor antagonist administration improves working memory in aging}

Consistent with the relationship between lower endogenous GABA(B)R expression and better working memory in aging, both systemic and intra-mPFC administration of a GABA(B)R antagonist (CGP55845) significantly improved working memory performance of aged rats. Indeed, with both routes of administration, doses of CGP55845 were identified which completely restored working memory performance in aged rats to a level on par with young performance. These cognitively enhancing effects are consistent with prior reports that have primarily focused on the efficacy of this class of GABA(B)R antagonists in improving hippocampal mediated cognition in young and aged rats (Mondadori et al., 1993; Froestl et al., 2004; Helm et al., 2005; Lasarge et al., 2009; Froestl, 2010; Kleschevnikov et al., 2012). Interestingly, systemic injections of the same doses of CGP55845 impaired young rat performance in the delayed response task. One interpretation of these differential effects in young and aged rats is that $\mathrm{GABA}(\mathrm{B}) \mathrm{R}$ blockade in young rats opposes GABAergic transmission that is optimal for working memory. Blocking GABA(B)R activity in young rats may shift the mPFC toward a hyperexcitable state which could ultimately be as deleterious to working memory as the excessive inhibition that may accompany advanced age. Indeed, in schizophrenia, interneuron dysfunction and PFC hyperexcitability are thought to contribute to impaired working memory, a hallmark feature of this disorder (Lewis et al., 2005; Yizhar et al., 2011). Alternatively, it is possible that the impairing effects of GABA(B)R blockade in young animals have a site of action that is distinct from the enhancing effects of this drug at advanced ages. Data to date support a model in which GABA(B) blockade in aged mPFC serves to attenuate the effects of postsynaptic and/or extrasynaptic GABA(B)Rs expressed by mPFC pyramidal neurons. However, GABA(B)Rs are also localized presynaptically where their blockade could contribute to excess GABA release and increased pyramidal neuron inhibition. It is interesting to speculate that in young animals, GABA(B)R antagonists might serve to disinhibit GABA terminals themselves, ultimately resulting in greater pyramidal neuron inhibition, an effect which could confer impaired working memory. It is notable that although a similar pattern of impaired performance in young rats was observed following both systemic and intra-mPFC administration of the GABA(B)R antagonist, the effects did not reach statistical significance when the drug was delivered intracerebrally. As such, it is important to consider the possibility that critical site of action for the impairing effects of GABA(B)R antagonists may be outside of the mPFC. Overall, a better understanding of the synaptic dynamics of GABA(B)R signaling in both the young and aged brain will be essential for clarifying the role of these receptors in normal cognition and in age-related cognitive disorders.

The current biochemical and pharmacological findings as well as several prior electrophysiological studies suggest that pyramidal neurons may be subject to greater inhibition in aged rats. However, it is also important to consider that numbers of both interneurons and inhibitory, i.e., symmetrical, synapses can decline with age (de Brabander et al., 1998; Wong et al., 2000; Jacobs et al., 2001; Poe et al., 2001; Uylings and de Brabander, 2002; Duan et al., 2003; Stranahan et al., 2012). In the current study, expression of VGAT, which is critical for packaging GABA into synaptic vesicles and thus should be present in all inhibitory terminals, was stable across ages. Although the VGAT data support a relative preservation of inhibitory terminals in this model, the failure of this measure to recapitulate the previous anatomical reports of reduced inhibitory synapse number may reflect insufficient sensitivity of the methodologies used here to detect inhibitory terminal loss in cortical microcircuits. Alternatively, it is certainly possible given the other dynamic changes in GABA signaling proteins reported here, that although overall synapse number is reduced, there is an upregulation of VGAT expression with age in remaining inhibitory synapses. Given the diversity of interneurons and evidence that interneuron subclasses can be differentially sensitive to changes with age (Potier et al., 1994; Shetty and Turner, 1998; Vela et al., 2003), it will be important in future work to determine whether the findings described here are a pervasive feature of aged PFC interneurons, or rather if these biochemical alterations reflect very robust but anatomically restricted effects in specific interneuron subclasses.

The present study provides evidence that GABAergic substrates in $\mathrm{mPFC}$ are dysregulated during normal aging. The pattern of changes in protein expression suggest that $\mathrm{mPFC}$ pyramidal neurons are subject to greater inhibition with advanced aging and that downregulation of $G A B A(B) R$ expression in these neurons reflects an effective compensatory mechanism for preserving working memory function. GABA(B)R expression was strongly and inversely related to working memory abilities such that lower expression was associated with better preservation of working memory function in aged rats, and GABA(B)R blockade effectively reversed age-related impairments in working memory. These findings highlight that altered excitatoryinhibitory dynamics within the aged PFC may contribute to working memory decline in aging, and that targeting GABA(B)Rs may provide therapeutic benefits for improving cognitive functions supported by this brain region.

\section{References}

Allen TA, Narayanan NS, Kholodar-Smith DB, Zhao Y, Laubach M, Brown TH (2008) Imaging the spread of reversible brain inactivations using fluorescent muscimol. J Neurosci Methods 171:30-38. CrossRef Medline Arnsten AF (2013) The neurobiology of thought: the groundbreaking discoveries of Patricia Goldman-Rakic 1937-2003. Cereb Cortex 23:22692281. CrossRef Medline

Arnsten AF, Cai JX, Murphy BL, Goldman-Rakic PS (1994) Dopamine D1 receptor mechanisms in the cognitive performance of young adult and aged monkeys. Psychopharmacology 116:143-151. CrossRef Medline

Beas BS, Setlow B, Bizon JL (2013) Distinct manifestations of executive dysfunction in aged rats. Neurobiol Aging 34:2164-2174. CrossRef Medline Biermann B, Ivankova-Susankova K, Bradaia A, Abdel Aziz S, Besseyrias V, Kapfhammer JP, Missler M, Gassmann M, Bettler B (2010) The sushi domains of GABAB receptors function as axonal targeting signals. J Neurosci 30:1385-1394. CrossRef Medline

Bizon JL, Foster TC, Alexander GE, Glisky EL (2012) Characterizing cognitive aging of working memory and executive function in animal models. Front Aging Neurosci 4:19. CrossRef Medline 
Bories C, Husson Z, Guitton MJ, De Koninck Y (2013) Differential balance of prefrontal synaptic activity in successful versus unsuccessful cognitive aging. J Neurosci 33:1344-1356. CrossRef Medline

Chiu CS, Brickley S, Jensen K, Southwell A, Mckinney S, Cull-Candy S, Mody I, Lester HA (2005) GABA transporter deficiency causes tremor, ataxia, nervousness, and increased GABA-induced tonic conductance in cerebellum. J Neurosci 25:3234-3245. CrossRef Medline

Conti F, Minelli A, Melone M (2004) GABA transporters in the mammalian cerebral cortex: localization, development and pathological implications. Brain Res Brain Res Rev 45:196-212. CrossRef Medline

Davis S, Rodger J, Hicks A, Mallet J, Laroche S (1996) Brain structure and task-specific increase in expression of the gene encoding syntaxin 1B during learning in the rat: a potential molecular marker for learning-induced synaptic plasticity in neural networks. Eur J Neurosci 8:2068-2074. CrossRef Medline

de Brabander JM, Kramers RJ, Uylings HB (1998) Layer-specific dendritic regression of pyramidal cells with ageing in the human prefrontal cortex. Eur J Neurosci 10:1261-1269. CrossRef Medline

Duan H, Wearne SL, Rocher AB, Macedo A, Morrison JH, Hof PR (2003) Age-related dendritic and spine changes in corticocortically projecting neurons in macaque monkeys. Cereb Cortex 13:950-961. CrossRef Medline

Enomoto T, Tse MT, Floresco SB (2011) Reducing prefrontal gammaaminobutyric acid activity induces cognitive, behavioral, and dopaminergic abnormalities that resemble schizophrenia. Biol Psychiatry 69: 432-441. CrossRef Medline

Frahm C, Engel D, Draguhn A (2001) Efficacy of background GABA uptake in rat hippocampal slices. Neuroreport 12:1593-1596. CrossRef Medline

Froestl W (2010) Chemistry and pharmacology of GABAB receptor ligands. Adv Pharmacol 58:19-62. CrossRef Medline

Froestl W, Mickel SJ, Schmutz M, Bittiger H (1996) Potent, orally active GABAB receptor antagonists. Pharmacol Rev Commun 8:127-133.

Froestl W, Gallagher M, Jenkins H, Madrid A, Melcher T, Teichman S, Mondadori CG, Pearlman R (2004) SGS742: the first GABAB receptor antagonist in clinical trials. Biochem Pharmacol 68:1479-1487. CrossRef Medline

Glisky EL (2007) Changes in cognitive function in human aging. In: Brain aging: models, methods, and mechanisms (Riddle DR, ed). Boca Raton, FL: CRC.

Glykys J, Mody I (2007) The main source of ambient GABA responsible for tonic inhibition in the mouse hippocampus. J Physiol 582:1163-1178. CrossRef Medline

Goldman-Rakic PS (1995) Cellular basis of working memory. Neuron 14: 477-485. CrossRef Medline

Goldman-Rakic PS (1996) Regional and cellular fractionation of working memory. Proc Natl Acad Sci U S A 93:13473-13480. CrossRef Medline

Goldman-Rakic PS, Brown RM (1981) Regional changes of monoamines in cerebral cortex and subcortical structures of aging rhesus monkeys. Neuroscience 6:177-187. CrossRef Medline

Gonzalez-Burgos G (2010) GABA transporter GAT1: a crucial determinant of GABAB receptor activation in cortical circuits? Adv Pharmacol 58:175204. CrossRef Medline

Gonzalez-Burgos G, Lewis DA (2008) GABA neurons and the mechanisms of network oscillations: implications for understanding cortical dysfunction in schizophrenia. Schizophr Bull 34:944-961. CrossRef Medline

Gonzalez-Burgos G, Rotaru DC, Zaitsev AV, Povysheva NV, Lewis DA (2009) GABA transporter GAT1 prevents spillover at proximal and distal GABA synapses onto primate prefrontal cortex neurons. J Neurophysiol 101:533-547. CrossRef Medline

Helm KA, Haberman RP, Dean SL, Hoyt EC, Melcher T, Lund PK, Gallagher M (2005) GABAB receptor antagonist SGS742 improves spatial memory and reduces protein binding to the cAMP response element (CRE) in the hippocampus. Neuropharmacology 48:956-964. CrossRef Medline

Jacobs B, Schall M, Prather M, Kapler E, Driscoll L, Baca S, Jacobs J, Ford K, Wainwright M, Treml M (2001) Regional dendritic and spine variation in human cerebral cortex: a quantitative golgi study. Cereb Cortex 11: 558-571. CrossRef Medline

Jensen K, Chiu CS, Sokolova I, Lester HA, Mody I (2003) GABA transporter-1 (GAT1)-deficient mice: differential tonic activation of GABAA versus GABAB receptors in the hippocampus. J Neurophysiol 90:2690-2701. CrossRef Medline

Jones KA, Borowsky B, Tamm JA, Craig DA, Durkin MM, Dai M, Yao WJ,
Johnson M, Gunwaldsen C, Huang LY, Tang C, Shen Q, Salon JA, Morse K, Laz T, Smith KE, Nagarathnam D, Noble SA, Branchek TA, Gerald C (1998) GABA(B) receptors function as a heteromeric assembly of the subunits GABA(B)R1 and GABA(B)R2. Nature 396:674-679. CrossRef Medline

Kaupmann K, Huggel K, Heid J, Flor PJ, Bischoff S, Mickel SJ, McMaster G, Angst C, Bittiger H, Froestl W, Bettler B (1997) Expression cloning of GABA(B) receptors uncovers similarity to metabotropic glutamate receptors. Nature 386:239-246. CrossRef Medline

Kaupmann K, Malitschek B, Schuler V, Heid J, Froestl W, Beck P, Mosbacher J, Bischoff S, Kulik A, Shigemoto R, Karschin A, Bettler B (1998) GABA(B)-receptor subtypes assemble into functional heteromeric complexes. Nature 396:683-687. CrossRef Medline

Kleschevnikov AM, Belichenko PV, Villar AJ, Epstein CJ, Malenka RC, Mobley WC (2004) Hippocampal long-term potentiation suppressed by increased inhibition in the Ts65Dn mouse, a genetic model of Down syndrome. J Neurosci 24:8153-8160. CrossRef Medline

Kleschevnikov AM, Belichenko PV, Faizi M, Jacobs LF, Htun K, Shamloo M, Mobley WC (2012) Deficits in cognition and synaptic plasticity in a mouse model of Down syndrome ameliorated by GABAB receptor antagonists. J Neurosci 32:9217-9227. CrossRef Medline

Kulik A, Vida I, Luján R, Haas CA, López-Bendito G, Shigemoto R, Frotscher M (2003) Subcellular localization of metabotropic GABA(B) receptor subunits $\mathrm{GABA}(\mathrm{B} 1 \mathrm{a} / \mathrm{b})$ and $\mathrm{GABA}(\mathrm{B} 2)$ in the rat hippocampus. J Neurosci 23:11026-11035. Medline

Kulik A, Vida I, Fukazawa Y, Guetg N, Kasugai Y, Marker CL, Rigato F, Bettler B, Wickman K, Frotscher M, Shigemoto R (2006) Compartmentdependent colocalization of Kir3.2-containing $\mathrm{K}+$ channels and GABAB receptors in hippocampal pyramidal cells. J Neurosci 26:4289-4297. CrossRef Medline

Lasarge CL, Bañuelos C, Mayse JD, Bizon JL (2009) Blockade of GABA(B) receptors completely reverses age-related learning impairment. Neuroscience 164:941-947. CrossRef Medline

Lewis DA, Hashimoto T, Volk DW (2005) Cortical inhibitory neurons and schizophrenia. Nat Rev Neurosci 6:312-324. CrossRef Medline

Luebke JI, Chang YM, Moore TL, Rosene DL (2004) Normal aging results in decreased synaptic excitation and increased synaptic inhibition of layer $2 / 3$ pyramidal cells in the monkey prefrontal cortex. Neuroscience 125 : 277-288. CrossRef Medline

McQuail JA, Bañuelos C, LaSarge CL, Nicolle MM, Bizon JL (2012) $\mathrm{GABA}(\mathrm{B})$ receptor GTP-binding is decreased in the prefrontal cortex but not the hippocampus of aged rats. Neurobiol Aging 33:1124 e1-12. CrossRef Medline

Minelli A, Brecha NC, Karschin C, DeBiasi S, Conti F (1995) GAT-1, a high-affinity GABA plasma membrane transporter, is localized to neurons and astroglia in the cerebral cortex. J Neurosci 15:7734-7746. Medline

Mondadori C, Jaekel J, Preiswerk G (1993) CGP 36742: the first orally active GABAB blocker improves the cognitive performance of mice, rats, and rhesus monkeys. Behav Neural Biol 60:62-68. CrossRef Medline

Moore TL, Schettler SP, Killiany RJ, Herndon JG, Luebke JI, Moss MB, Rosene DL (2005) Cognitive impairment in aged rhesus monkeys associated with monoamine receptors in the prefrontal cortex. Behav Brain Res 160:208-221. CrossRef Medline

Murray AJ, Sauer JF, Riedel G, McClure C, Ansel L, Cheyne L, Bartos M, Wisden W, Wulff P (2011) Parvalbumin-positive CA1 interneurons are required for spatial working but not for reference memory. Nat Neurosci 14:297-299. CrossRef Medline

Paxinos G, Watson C (2005) The rat brain in stereotaxic coordinates, Ed 5. Boston: Elsevier.

Pinard A, Seddik R, Bettler B (2010) GABAB receptors: physiological functions and mechanisms of diversity. Adv Pharmacol 58:231-255. CrossRef Medline

Poe BH, Linville C, Brunso-Bechtold J (2001) Age-related decline of presumptive inhibitory synapses in the sensorimotor cortex as revealed by the physical dissector. J Comp Neurol 439:65-72. CrossRef Medline

Potier B, Krzywkowski P, Lamour Y, Dutar P (1994) Loss of calbindinimmunoreactivity in CA1 hippocampal stratum radiatum and stratum lacunosum-moleculare interneurons in the aged rat. Brain Res 661:181188. CrossRef Medline

Ragozzino ME (2002) The effects of dopamine D(1) receptor blockade in 
the prelimbic-infralimbic areas on behavioral flexibility. Learn Mem 9:18-28. CrossRef Medline

Robbins TW, James M, Owen AM, Sahakian BJ, Lawrence AD, McInnes L, Rabbitt PM (1998) A study of performance on tests from the CANTAB battery sensitive to frontal lobe dysfunction in a large sample of normal volunteers: implications for theories of executive functioning and cognitive aging. Cambridge Neuropsychological Test Automated Battery. J Int Neuropsychol Soc 4:474-490. Medline

Salthouse TA, Atkinson TM, Berish DE (2003) Executive functioning as a potential mediator of age-related cognitive decline in normal adults. J Exp Psychol Gen 132:566-594. CrossRef Medline

Shetty AK, Turner DA (1998) Hippocampal interneurons expressing glutamic acid decarboxylase and calcium-binding proteins decrease with aging in Fischer 344 rats. J Comp Neurol 394:252-269. CrossRef Medline

Sloan HL, Good M, Dunnett SB (2006) Double dissociation between hippocampal and prefrontal lesions on an operant delayed matching task and a water maze reference memory task. Behav Brain Res 171:116-126. CrossRef Medline

Stefani MR, Moghaddam B (2005) Systemic and prefrontal cortical NMDA receptor blockade differentially affect discrimination learning and setshift ability in rats. Behav Neurosci 119:420-428. CrossRef Medline

St Onge JR, Abhari H, Floresco SB (2011) Dissociable contributions by prefrontal D1 and D2 receptors to risk-based decision making. J Neurosci 31:8625-8633. CrossRef Medline

Stranahan AM, Jiam NT, Spiegel AM, Gallagher M (2012) Aging reduces total neuron number in the dorsal component of the rodent prefrontal cortex. J Comp Neurol 520:1318-1326. CrossRef Medline

Taylor JR, Birnbaum S, Ubriani R, Arnsten AF (1999) Activation of cAMPdependent protein kinase $\mathrm{A}$ in prefrontal cortex impairs working memory performance. J Neurosci 19:RC23. Medline

Uylings HB, de Brabander JM (2002) Neuronal changes in normal human aging and Alzheimer's disease. Brain Cogn 49:268-276. CrossRef Medline

Uylings HB, Groenewegen HJ, Kolb B (2003) Do rats have a prefrontal cortex? Behav Brain Res 146:3-17. CrossRef Medline

Vela J, Gutierrez A, Vitorica J, Ruano D (2003) Rat hippocampal GABAer- gic molecular markers are differentially affected by ageing. J Neurochem 85:368-377. CrossRef Medline

Vigot R, Barbieri S, Bräuner-Osborne H, Turecek R, Shigemoto R, Zhang YP, Luján R, Jacobson LH, Biermann B, Fritschy JM, Vacher CM, Müller M, Sansig G, Guetg N, Cryan JF, Kaupmann K, Gassmann M, Oertner TG, Bettler B (2006) Differential compartmentalization and distinct functions of GABAB receptor variants. Neuron 50:589-601. CrossRef Medline

Wang M, Yang Y, Wang CJ, Gamo NJ, Jin LE, Mazer JA, Morrison JH, Wang XJ, Arnsten AF (2013) NMDA receptors subserve persistent neuronal firing during working memory in dorsolateral prefrontal cortex. Neuron 77:736-749. CrossRef Medline

Wang Y, Neubauer FB, Lüscher HR, Thurley K (2010) GABAB receptordependent modulation of network activity in the rat prefrontal cortex in vitro. Eur J Neurosci 31:1582-1594. CrossRef Medline

Wass C, Pizzo A, Sauce B, Kawasumi Y, Sturzoiu T, Ree F, Otto T, Matzel LD (2013) Dopamine D1 sensitivity in the prefrontal cortex predicts general cognitive abilities and is modulated by working memory training. Learn Mem 20:617-627. CrossRef Medline

White JH, Wise A, Main MJ, Green A, Fraser NJ, Disney GH, Barnes AA, Emson P, Foord SM, Marshall FH (1998) Heterodimerization is required for the formation of a functional GABA(B) receptor. Nature 396: 679-682. CrossRef Medline

Wong TP, Marchese G, Casu MA, Ribeiro-da-Silva A, Cuello AC, De Koninck Y (2000) Loss of presynaptic and postsynaptic structures is accompanied by compensatory increase in action potential-dependent synaptic input to layer $\mathrm{V}$ neocortical pyramidal neurons in aged rats. J Neurosci 20:8596-8606. Medline

Yizhar O, Fenno LE, Prigge M, Schneider F, Davidson TJ, O’Shea DJ, Sohal VS, Goshen I, Finkelstein J, Paz JT, Stehfest K, Fudim R, Ramakrishnan C, Huguenard JR, Hegemann P, Deisseroth K (2011) Neocortical excitation/inhibition balance in information processing and social dysfunction. Nature 477:171-178. CrossRef Medline

Zaitsev AV, Povysheva NV, Gonzalez-Burgos G, Rotaru D, Fish KN, Krimer LS, Lewis DA (2009) Interneuron diversity in layers 2-3 of monkey prefrontal cortex. Cereb Cortex 19:1597-1615. CrossRef Medline 